\title{
O DANO EXTRAPATRIMONIAL TRABALHISTA REGULAMENTADO PELA LEI 13.467/17
}

\author{
Danna Catharina Mascarello Luciani \\ Pontifícia Universidade Católica do Paraná - PUC/PR, \\ Paraná. \\ dannacml@hotmail.com \\ Marco Antonio César Villatore \\ Universidade Federal de Santa Catarina - UFSC, Santa \\ Catarina. \\ prof.villatore@gmail.com
}

\begin{abstract}
RESUMO: O presente trabalho busca levantar breves reflexões quanto a coerência da regulamentação trazida pela reforma trabalhista para o dano extrapatrimonial decorrente das relações de trabalho em face do ordenamento já utilizado pela jurisprudência quando do julgamento de casos concretos. Utilizou-se, para tanto, conceitos já consolidados na doutrina e na jurisprudência, posicionamentos doutrinários quanto as novidades legislativas e a jurisprudência dos órgãos da justiça do trabalho em sua interpretação das normas do direito comum em consonância com os princípios do direito do trabalho e da interpretação das novas normas, trazidas pela reforma trabalhista. Considerou-se, por fim, que as novas normas são incompatíveis com o sistema jurídico brasileiro e acarretam no cerceamento de direitos fundamentais do trabalhador, violando um dos fundamentos da república e vários dos princípios da ordem constitucional vigente.
\end{abstract}

PALAVRAS-CHAVE: Responsabilidade civil. Dano extrapatrimonial. Reforma trabalhista.

\section{The labor's non-pecuniary damage regulated by the Law 13.467/17}

\begin{abstract}
The present work seeks to raise brief reflections on the coherence of the assistance for the labor reform for the extra-financial damage resulting from labor relations in the face of the right to use jurisprudence when judging concrete cases. For this purpose, concepts already consolidated in doctrine and jurisprudence, doctrinal positions for new legislation and jurisprudence of labor law bodies are used in their interpretation of the norms of common law in accordance with the principles of labor law and interpretation of the new norms, brought about by the labor reform. It was finally considered that the new norms are incompatible with the Brazilian legal system and do not have a framework of fundamental rights of the worker, violating the foundations of the republic and several of the principles of the current constitutional order.
\end{abstract}

KEYWORDS: Civil liability. Non-pecuniary damage. Labor reform.

\section{INTRODUÇÃO}

Em 2017, após conturbados debates no Congresso Nacional e acalorada movimentação social, foi publicada a lei 13.467, que alterou diversos artigos do Decreto-Lei $\mathrm{n}^{\circ} 5.452$ de 1943 (a Consolidação das Leis do Trabalho). Entre as alterações promovidas está a inclusão dos artigos 223-A a 223-G, que, suscintamente, regulamentaram a responsabilidade civil do trabalhador em face do dano extrapatrimonial causado pelas circunstâncias do trabalho prestado. 
Antes disso, os danos extrapatrimoniais decorrentes da relação de trabalho eram calculados com o uso de normas externas ao direito trabalhista, mas que, por expressa previsão legal (antigo artigo $8^{\circ}$, parágrafo único da CLT), eram consideradas fontes subsidiárias (naquilo que não fossem incompatíveis com os princípios do Direito do Trabalho), quais sejam, as normas do direito comum.

Logo, a responsabilização por danos extrapatrimoniais, além do caráter indenizatório (ou seja, ressarcimento pelos danos sofridos), tinha também caráter pedagógico (ou seja, serviria para demonstrar ao causador do dano que isso não deveria ser corriqueiro, cabendo ao empregador evitar que a situação danosa se mantenha, seja para o indenizado, seja para os possíveis afetados), devendo ser calculada de acordo com a extensão do dano sofrido, de modo a ressarcir, integralmente, a vítima do dano pelos efeitos sofridos.

Com as novas regras, que entraram em vigor em 11 de novembro de 2017 (após a vacacio legis de 120 dias prevista no artigo $6^{\circ}$ da lei 13.467/17), os danos extrapatrimoniais decorrentes da relação de trabalho seriam regulados apenas pelo disposto no Título II-A da CLT. Isso impossibilitou a utilização do artigo $8^{\circ}, \S 1^{\circ}$ da CLT - que, conforme sua nova redação, permite a utilização do direito comum como fonte subsidiária do direito do trabalho - no caso do dano extrapatrimonial.

Ainda, as novas regras definiram balizas aos valores referentes à indenização devida em cada caso, tornando precário o ideal realmente buscado pela indenização por danos extrapatrimoniais prevista no Código Civil: a real indenização de acordo com a extensão dos danos sofridos, e vinculando tal índice ao salário recebido pelo trabalhador.

No presente estudo, partindo das circunstâncias apontadas em epígrafe, pretendemos analisar os conceitos e as mudanças trazidos pela reforma no que tange a responsabilidade civil por danos extrapatrimoniais, balizando nossa pesquisa nos princípios que regem o direito (processual e material) do trabalho e o ordenamento constitucional vigente. Para tanto, construiremos o raciocínio a partir de uma cronologia e de pesquisa nas demais áreas do direito utilizadas nesse contexto, interpretando-as de maneira complementar.

Cumpre ressaltar aqui que esse artigo está focado na regulamentação da responsabilidade civil dada pela lei 13.467/17, de modo algum questionando a já pacificada possibilidade de responsabilização por danos extrapatrimoniais nas relações trabalhistas, apenas a sua nova regulamentação.

\section{O DANO EXTRAPATRIMONIAL}

O direito civil, em especial a parte da Responsabilidade Civil, divide "dano" em patrimonial (ou material) e extrapatrimonial (ou imaterial, ou ainda moral para alguns). Enquanto o dano material possui possibilidade física de comprovação, o dano extrapatrimonial atinge características intrínsecas ao indivíduo, insubstituíveis e, por tanto, apenas indenizáveis (não se trata de perder patrimônio e depois recuperá-lo, mas sim de ser ressarcido pela violação de suas individualidades) (TARTUCE, 2017).

A etimologia da palavra extrapatrimonial já tem muito a nos ensinar: "Extra”, originário do latim (com sentido de fora de, para fora de) ${ }^{1}$, quando utilizado como prefixo, aponta para aquilo que está além, que não pode ser incluso em determinado grupo. "Patrimonial”, por sua

1 Dicionário Priberam da Língua Portuguesa [em linha], 2008-2013, https://dicionario.priberam.org/extra [consultado em 24-11-2018]. 
vez, é "Relativo a bem ou conjunto de bens, materiais ou naturais, reconhecidos por sua importância cultural". Com isso, percebe-se que dano extrapatrimonial abrange tudo aquilo que não pode ser considerado patrimônio, aquilo que está além do material, do físico, mas que mesmo assim integra determinada esfera de direitos (que, conforme o raciocínio firmado no Enunciado $\mathrm{n}^{\circ} 456^{2}$ da V Jornada de Direito Civil, pode ser tanto de direitos individuais quanto de direitos coletivos).

\title{
1.1. Do dano moral
}

Flávio Tartuce (2017), ao conceituar “danos morais”, utiliza, em diversos momentos, essa expressão como sinônimo de "danos extrapatrimoniais" (como quando explica a possibilidade de outras formas de compensação do dano além da prestação pecuniária).

\begin{abstract}
A melhor corrente categórica é aquela que conceitua os danos morais como lesão a direitos da personalidade, sendo essa a visão que prevalece na doutrina brasileira. (...)

Além do pagamento de uma indenização em dinheiro, presente o dano moral, é viável uma compensação in natura, conforme reconhece enunciado aprovado na VII Jornada de Direito Civil (2015): “A compensação pecuniária não é o único modo de reparar o dano extrapatrimonial, sendo admitida a reparação in natura, na forma de retração pública ou outro meio" (Enunciado n. 589).
\end{abstract}

Mesmo assim, a redação do artigo 223-B da CLT aponta para o entendimento do legislador no sentido de que dano extrapatrimonial do dano moral são coisas distintas (sendo aquele o gênero do qual esse é espécie, ao lado do dano existencial):

Art. 223-B. Causa dano de natureza extrapatrimonial a ação ou omissão que ofenda a esfera moral ou existencial da pessoa física ou jurídica, as quais são as titulares exclusivas do direito à reparação.

O dano moral, conforme ensina Rodolfo Pamplona Filho (2001, p. 164-179), pode ser definido como:

\begin{abstract}
O dano moral consiste no prejuízo ou lesão de interesses e bens, cujo conteúdo não é pecuniário, nem comercialmente redutível a dinheiro. Em outras palavras, podemos afirmar que o dano moral é aquele que lesiona a esfera personalíssima da pessoa, violando sua intimidade, vida privada, honra e imagem, bens jurídicos tutelados constitucionalmente.
\end{abstract}

Logo, trata-se de ofensa à personalidade, a uma esfera individual de direitos que, mesmo imateriais, são constitucionalmente tutelados.

\subsection{Do dano existencial}

Em contrapartida, Flaviana Soares (2009), em sua obra, aborda o dano existencial (como desdobramento do dano extrapatrimonial), e ensina que:

A expressão dano existencial foi cunhada por Paolo Cendon e Patrizia Ziviz para agrupar vários casos que não poderiam, a rigor, ser decididos sob o rótulo de dano moral ou dano biológico, pois a única coisa que os acomunava era o fato de não se

2 A expressão ‘dano', no art. 944, abrange não só os danos individuais, materiais ou imateriais, mas também os danos sociais, difusos, coletivos e individuais homogêneos, a serem reclamados pelos legitimados para propor ações coletivas. 


\begin{abstract}
tratar de danos patrimoniais. A partir da década de noventa, a jurisprudência italiana começou a adotar tal nomenclatura, considerando como dano existencial a lesão a outros interesses de natureza constitucional inerentes à pessoa, que não se confundiam com a transitória perturbação do estado de ânimo da vítima, nem com a lesão a integridade psíquica e física da pessoa. (grifos nossos)
\end{abstract}

Assim, percebe-se que o posicionamento doutrinário é no sentido de que o dano existencial é aquele que atinge direitos fundamentais individuais, refletindo diretamente na integridade da pessoa, e causando sequelas profundas e dificilmente corrigíveis.

Para a jurisprudência trabalhista brasileira, o reconhecimento do dano existencial está vinculado à prova de que tal violação de direitos acarretou em danos irreparáveis na esfera dos direitos fundamentais do indivíduo, conforme decisão, em 07/08/2018, pela $6^{\text {a }}$ Turma do Tribunal Regional do Trabalho da $9^{a}$ Região:

\footnotetext{
TRT-PR-07-08-2018 DANOS EXISTENCIAIS - Ao empregado que postula indenização por danos existenciais, cabe provar que, em virtude do ilícito patronal, sofreu sério prejuízo naquilo que decidiu fazer com sua vida (v.g., algum projeto educacional ou social), na fruição de prazeres derivados de atividades extralaborais (v.g., prática de esportes, realização de atividades religiosas, lazer), nas suas relações pessoais (v.g., convivência com familiares e amigos), etc. Assim, não basta a mera prestação de labor além da jornada ordinária legal, por exemplo, para se deferir, como consequência automática, a indenização por dano existencial. Há a necessidade de comprovação de que o cumprimento dessas horas extras, efetivamente, causou relevante prejuízo a algum projeto preestabelecido do trabalhador, arruinou algum relacionamento familiar, impediu a realização de atividades alheias ao contrato, etc. Recurso da Reclamante a que se nega provimento. TRT-PR-08980-2015-863-09-00-2-ACO12372-2018 - 6A. TURMA. Relator: PAULO RICARDO POZZOLO. Publicado no DEJT em 07-08-2018.
}

Conclui-se, portanto, que dano extrapatrimonial é gênero do qual são espécies o dano moral e o dano existencial, que podem ser diferenciados pela natureza dos direitos violados e pela gravidade dessa violação: enquanto o dano moral viola, de maneira reparável e passageira, os direitos de personalidade do indivíduo, o dano existencial acarreta na irreparabilidade do dano e em seus reflexos latentes em diversos direitos individuais constitucionalmente previstos.

\title{
2. O DANO EXTRAPATRIMONIAL TRABALHISTA
}

\subsection{Regulamentação anterior}

O Dano Extrapatrimonial era, em qualquer situação, julgado pela justiça comum. Com o advento da Emenda Constitucional n 45 de 2004, o dano imaterial decorrente de relações de trabalho passou a ser julgado pela Justiça do Trabalho, e assim o é até hoje. A transferência de competência demonstrou que se trata de matéria parecida, mas não igual, o que leva a necessidade de uma regulamentação específica para o âmbito laboral.

Como não houve regulamentação especial, os tribunais passaram - de acordo com a possibilidade dada pela antiga redação do artigo $8^{\circ}$, parágrafo único da CLT (que afirmava: "O direito comum será fonte subsidiária do direito do trabalho, naquilo em que não for incompatível com os princípios fundamentais deste") - a utilizar as normas do direito comum para decidir sobre esse tema, interpretando-as de maneira coerente com os princípios trabalhistas (FACCHINI NETO; GOLDSCHMIDT 2017, p. 219-254). 
Disciplina o assunto o Título IX, “da Responsabilidade Civil”, do Código Civil. Nesse Título encontra-se o artigo 927 ("aquele que, por ato ilícito [...], causar dano a outrem, fica obrigado a repará-lo"), que define que a responsabilidade pela reparação (consequência) do dano (causa) é daquele que o provocou. Ainda, o Código Civil (artigo 932, caput e inciso III - "são também responsáveis pela reparação civil: [...] III - o empregador ou comitente, por seus empregados, serviçais e prepostos, no exercício do trabalho que lhes competir, ou em razão dele;") prevê, expressamente, que o dano decorrente de relação de trabalho gera responsabilidade civil, reforçando a interpretação dada pelos magistrados no sentido da aplicabilidade das normas de direito comum referentes a esse tema.

Confirmada a aplicação do Código Civil, passamos ao quantum indenizatório a ser fixado. Estabelece o mesmo código, em seu artigo 944, que "a indenização mede-se pela extensão do dano". Logo, independentemente da proporção dos efeitos do dano, esses devem ser indenizados, para que haja a correta transferência dos efeitos negativos ao seu causador, de modo que a vítima não precise arcar com prejuízos dos quais não tem culpa.

\subsection{Regulamentação dada pela reforma trabalhista}

Em 2017, na contramão da jurisprudência já consolidada e de diversos posicionamentos doutrinários, o Congresso Nacional aprova, às pressas, o Projeto de Lei $n^{\circ}$ 6.787/16, que teve mais de 800 emendas $^{3}$ mesmo no curto período em que tramitou (fora apresentado em 23/12/ 2016 e publicado, pela Presidência da República, em 13/07/2017, totalizando pouco menos de 7 meses de apreciação pelo Poder Legislativo). Tal projeto foi convertido em lei em 13 de julho de 2017, tornando-se a lei $\mathrm{n}^{\mathrm{o}} 13.467 / 17$.

Dentre as alterações, trazidas sob o argumento de aprimoramento e atualização das relações de trabalho ${ }^{4}$, está a inclusão do Título II-A (do artigo 223-A ao 223-G), que trata "do Dano Extrapatrimonial".

Já no primeiro artigo do Título (art. 223-A), o legislador definiu: “aplicam-se à reparação de danos de natureza extrapatrimonial decorrentes da relação de trabalho apenas os dispositivos deste Título". Ou seja, definiu-se pela utilização de numerus clausus, o que não condiz com a dinamicidade da sociedade moderna (SANTOS, 2017) e inviabiliza a continuidade da norma, que se torna obsoleta em um curto período de tempo por ser incapaz de regulamentar, efetivamente, diferentes e inovadoras relações.

Restringir diversas situações a poucos, e rasos, artigos, retirando a aplicabilidade dos já utilizados dispositivos do Código Civil é retirar dos magistrados (e de todo o Poder Judiciário) a sua maior, e mais complexa, tarefa: interpretar (COELHO; LOPES, 2017), de maneira sistemática, os dispositivos de todas as áreas do direito, ao invés de realizar a mera leitura, isolada, de um dispositivo legal, e aplicá-los ao caso concreto, o que já foi considerado inconstitucional por magistrados da justiça do trabalho ${ }^{5}$.

O estudo do artigo seguinte (223-B) requer maiores cuidados. Para fins de melhor elucidação dos componentes desse artigo, optamos por dividi-lo:

\footnotetext{
3 Disponível em: http://www.camara.gov.br/proposicoesWeb/prop_emendas?idProposicao=2122076\&subst=0

4 PL nº 6.787/16. Disponível no site da Câmara dos Deputados.

5 Enunciado Aglutinado $\mathrm{n}^{\mathrm{o}} 5$ da Comissão 2 da $2^{\mathrm{a}}$ Jornada de Direito Material e Processual do Trabalho.
} 
$\mathrm{Na}$ primeira parte (“causa dano de natureza extrapatrimonial a ação ou omissão que ofenda a esfera moral ou existencial [...]”), o dano extrapatrimonial é dividido em esferas, utilizando-se de conceitos já consagrados na doutrina civilista para abranger situações diversas. Entretanto, tal regulamentação foi insuficiente, uma vez que ignorou a existência dos danos estéticos (SIMÃO, 2017) (aqui, interpreta-se a Súmula $387^{6}$ do STJ no sentido de que dano moral e estético são coisas distintas e que podem ser pedidas cumulativamente em juízo).

Em sequência, esclarece o mesmo artigo: “da pessoa física ou jurídica”. Aqui, o legislador tornou lei o que a jurisprudência já tinha pacificado: pessoa jurídica é titular de direitos extrapatrimoniais, logo, pode ser vítima de danos a esses direitos (Súmula 227 do STJ: “A pessoa jurídica pode sofrer dano moral").

Por fim, tal artigo aponta para: "as quais são as titulares exclusivas do direito à reparação". Nesse momento, o legislador opta por excluir a possibilidade de dano em ricochete, impossibilitando que terceiros (alheios a relação de trabalho) possam pleitear em juízo o ressarcimento por danos indiretos sofridos em decorrência de ação ou omissão danosa ao trabalhador com quem são ligados (temos como exemplo aqui a viúva e os filhos que não são considerados titulares do direito ao ressarcimento pela morte por acidente de trabalho de seu marido/pai) (COELHO; LOPES, 2017).

Nesse ponto, a reforma trabalhista sofre severas críticas, sob a ótica de sua incompatibilidade com a Constituição Federal, como defendido por Cassio Colombo Filho (2017), quando ensina que:

Logo, a limitação dos art. 223-A e 223-B da Lei 13.467 da aplicação exclusiva da lei trabalhista para os infortúnios do trabalho e indenização unicamente à vítima, ofende a letra dos art. $1^{\circ}$, III e $5^{\circ}, \mathrm{V}$ da Constituição Federal, invade a esfera de direitos extracontratuais, limitando-os por contrato, e não pode ter o condão de revogar os art. 186 e 948 do Código Civil.

Em contrapartida, outros, como Marcos Avelar (2017), posicionam-se pela correta definição da impossibilidade de danos em ricochete, uma vez que isso nunca esteve previsto no ordenamento jurídico e que poderia causar certa instabilidade do sistema, considerando a magnitude do alcance indireto de um fato.

Há, ainda, um terceiro posicionamento, no sentido de que terceiros podem ser afetados diretamente por um dano causado a alguém, caso que não se pode confundir com o dano indireto ou em ricochete (SANTOS, 2017), tornando-se o terceiro titular do direito à indenização (posicionamento defendido por Nelson Rosenvald (2017), Des. Sebastião Geraldo de Oliveira ${ }^{7}$, Anderson Schreiber (2009, p. 59-60), citado pelo Desembargador em sua decisão e pelo magistrados da $2^{\text {a }}$ Jornada do Direito Material e Processual do Trabalho ${ }^{8}$ ).

Enquanto os legisladores tiveram como objetivo da Reforma Trabalhista a redução da margem de atuação do Poder Judiciário, a este caberá a uniformização da aplicabilidade das normas nos casos concretos. Para tanto, espera-se posicionamento rápido e amplo dos órgãos da justiça do trabalho, de maneira a permitir uma interpretação, por todos, seguindo os mesmos

6 É lícita a cumulação das indenizações de dano estético e dano moral

7 TRT $3^{\text {a }}$ Região. 01019-2007-042-03-00-3-RO, onde fundamenta sua decisão com: "Embora o acidente repercuta mais intensamente sobre a própria vítima, projeta seus reflexos dolorosos sobre todos que de alguma forma mantém vínculos afetivos com ela."

8 Enunciado $n^{\circ}$ 20. DANO EXTRAPATRIMONIAL: LIMITES E OUTROS ASPECTOS. Danos extrapatrimoniais. o artigo 223-B da clt, inserido pela lei 13.467, não exclui a reparação de danos sofridos por terceiros (danos em ricochete), bem como a de danos extrapatrimoniais ou morais coletivos, aplicando-se, quanto a estes, as disposições previstas na Lei 7.437/1985 e no título III do código de defesa do consumidor. 
preceitos e chegando a resultados parecidos, do dispositivo ora estudado e das outras alterações também trazidas pela reforma trabalhista.

Outra novidade oriunda da reforma trabalhista foi que, no mesmo título (Título II-A “do Dano Extrapatrimonial"), o legislador optou por definir índices para o cálculo do dano moral, balizando o alcance da restituição devida em caso de dano.

Com isso, os danos provenientes de relação de trabalho passaram a ser definidos em valores incompatíveis com o praticado em situações alheias a relação laboral, embora os reflexos sejam muito parecidos. É nesse sentido o defendido por Cassio Colombo Filho (2017) em seu artigo, quando ensina:

\begin{abstract}
Ainda que se permitisse a tarifação dos danos morais, o que se admite apenas por amor ao argumento, o tabelamento proposto não subsistiria, pois como aqui demonstrado, além de ofender a dignidade da pessoa humana, ela propicia discriminação odiosa, na medida em que a vida de trabalhadores melhor remunerados vale mais que a dos humildes. A dor pela lesão de um gerente ou encarregado pode ser compensada com valor maior que a de um "auxiliar de serviços gerais"? Além disso, pode acarretar indenizações em valores pífios, que obviamente descaracterizarão a finalidade concretizadora de qualquer indenização. Aqui também nítida a inconstitucionalidade por violência aos art. $1^{\circ} \mathrm{III}$ e $5^{\circ}$, da Constituição da República.
\end{abstract}

Cumpre relembrar que as normas do direito comum determinam que a responsabilização será correspondente ao dano causado, e não ao valor da relação entre o responsável pelo dano e sua vítima.

Ainda, a Medida Provisória nº 808/17 tentou remediar os efeitos da reforma nesse aspecto, restringindo a aplicação desses dispositivos e impedindo tal aplicação nos casos de morte. Entretanto, a Medida Provisória perdeu sua eficácia (uma vez que não foi aprovada pelo Congresso Nacional), logo, mantém-se o previsto na lei 13.467/17.

Percebemos, portanto, que os limites trazidos pelo legislador acerca do dano extrapatrimonial causaram mais complicações do que resolveram problemas: trata-se de uma tentativa de individualizar ramos do direito, os quais devem sempre ser interpretados de maneira sistemática, e de reduzir o campo de atuação do Poder Judiciário, sem que haja a ampla regulamentação dos casos concretos (o que torna as inovações insuficientes para que sejam fonte única do direito trabalhista). Além disso, a incorreta escolha pela impossibilidade de ampliação dos afetados pelos danos causados gera certo desconforto, uma vez que impede titulares de direitos (mesmo que reflexo) de postular por seu ressarcimento. Por fim, a escolha por balizar o quantum indenizatório leva-nos a incoerência sistêmica, em que direito comum e direito trabalhista possuem índices muito diferentes para situações muito parecidas.

\title{
3. INCOMPATIBILIDADE DAS NOVAS NORMAS COM O ORDENA- MENTO JURÍDICO
}

Nenhuma norma do ordenamento jurídico vigente pode ser interpretada de maneira isolada e todas devem ser compreendidas a partir da norma hierarquicamente superior. Por isso, em primazia, é importante atentar-se ao disposto no artigo $5^{\circ}$, incisos V e X, da Constituição Federal:

V - É assegurado o direito de resposta, proporcional ao agravo, além da indenização por dano material, moral ou à imagem.

X - são invioláveis a intimidade, a vida privada, a honra e a imagem das pessoas, assegurado o direito a indenização pelo dano material ou moral decorrente de sua violação. 
Nesse trecho constitucional, percebemos que é direito fundamental da vítima a indenização por danos decorrentes de violação de direitos materiais e imateriais. Além disso, em momento algum a carta magna traz limites ao dever de indenizar, nem tenta definir quais afetados são titulares desse direito e quais não são.

O limite imposto pelo novo ordenamento (seja no quantum, seja na pessoalidade do direito) ao direito de indenização caracteriza ofensa direta ao texto constitucional, além de desrespeitar um dos fundamentos da República Federativa do Brasil: "IV - os valores sociais do trabalho e da livre iniciativa", e também os princípios da igualdade, isonomia e segurança jurídica, uma vez que a definição pela inexistência do dano indireto "vai na contramão das tendências da responsabilidade civil contemporânea que, em vez de restringir, tem ampliado a titularidade dos danos na hipótese ora em destaque, não podendo a norma legal restringir o que a Constituição não limita" (FACCHINI NETO, 2017, p. 219-254).

Além disso, a vinculação do valor de um direito ao salário recebido, e não à extensão do dano, pode levar a interpretação de que o direito daquele que ganha mais, vale mais, e os direitos fundamentais não podem ser assim interpretados.

Consideramos, portanto, que as normas devem ser revistas, de maneira a se adequarem ao sistema jurídico vigente, de forma a possibilitar uma aplicação legalista e coerente por parte do Poder Judiciário.

\section{CONCLUSÃo}

Faz-se necessário o conhecimento de certos conceitos antes do início de um estudo não tão raso do tema. Para isso, depreende-se do presente artigo que dano extrapatrimonial são os efeitos de uma ação ou omissão daquele que deveria agir com cautela, de modo a evitar causar danos a outros. Nesse sentido, a responsabilidade civil por dano extrapatrimonial vem no sentido de transferir da vítima para o agente os efeitos negativos causados por ação desse, desincumbindo a vítima de arcar com prejuízos para os quais não concorreu.

Dentro dos danos extrapatrimoniais estão os danos morais (relativos ao momento, a um sofrimento passageiro sofrido pela vítima), os danos existenciais (danos que deixam sequelas na existência do indivíduo, prejudicando suas relações sociais e suas projeções futuras) e os danos estéticos (ligados a aparência do indivíduo, que, quando afetada, interfere no modo como esse se vê perante a sociedade), sendo que esses últimos foram ignorados pela reforma trabalhista.

Sempre houve o dano extrapatrimonial decorrente das relações de trabalho. Antes eram julgados pela justiça comum. Então, passaram a ser julgados pela justiça trabalhista com a utilização de dispositivos do direito comum. Por fim, objetivou a Lei 13.467/17 regulamentar tais situações de modo a tornar o julgamento na justiça laboral independente da justiça e di direito comuns.

Entretanto, essa regulamentação (feita as pressas) não se atentou a diversas características dos casos em tela, como a necessidade de ressarcir a vítima por todo o dano sofrido e a possibilidade de ocorrência de dano indireto. A lógica decorrente desses fatores seria a aplicação subsidiária das normas do direito comum. Em decorrência da restrição definida no artigo 223-A da CLT, essa aplicação subsidiária não é possível, deixando o direito laboral desprovido de normas capazes de atender, satisfatoriamente, as necessidades sociais que levam o individuo a acionar o Poder Judiciário. 
Com isso, a presente pesquisa teve como resultado a observação de que os direitos do trabalhador estão sendo cerceados, acarretando em grave desvalorização dos direitos pessoais do individuo que configura no polo mais fraco da relação de trabalho. Essa desvalorização vai de encontro a um dos fundamentos dessa república e cerceia direitos fundamentais (previstos no artigo $5^{\circ}$ da Constituição Federal). Logo, tais normas devem ser consideradas inconstitucionais, não devendo ser aplicadas no plano prático.

\section{REFERÊNCIAS}

AVELAR, Marcos. O não começo do dano moral em ricochete. Disponível em: http://www.trabalhismoemdebate.com.br/2017/09/o-nao-comeco-do-dano-moral-em-ricochete/. Acesso em 05 set. 2018.

COELHO, Luciano Augusto de Toledo. LOPES, Marcus Aurélio. Breves comentários ao novo regime do dano extrapatrimonial na justiça do trabalho. IX Amatra, 13 nov. 2017. Disponível em: http://www.amatra9.org.br/breves-comentarios-ao-novo-regime-do-dano-extrapatrimonialna-justica-do-trabalho-luciano-coelho-e-marcus-aurelio-lopes/. Acesso em 05 set. 2018.

COLOMBO FILHO, Cassio. O “dilema do bonde" e a reforma trabalhista. Revista do TRT 9" Região. Volume 6, Número 61, julho/agosto de 2017. Disponível em: https://agindodireito.com.br/wpcontent/uploads/2017/12/RevistaTRT-9-Reforma-Trabalhista.pdf. Acesso em 05 set. 2018.

FACCHINI NETO, Eugênio. GOLDSCHMIDT, Rodrigo. Tutela aquiliana do empregado: considerações sobre o novo sistema de reparação civil por danos extrapatrimoniais na área trabalhista. Revista dos Tribunais, vol. 984, out. 2017, p. 219-254. DTR\2017\6423

PAMPLONA FILHO, Rodolfo. A liquidação da reparação do dano moral trabalhista. Revista de Direito do Trabalho, vol. 104, out./dez. de 2001, p. 164-179. DTR\2001\446

ROSENVALD, Nelson. O novo dano moral trabalhista: um ensaio sobre a cegueira (do legislador). Disponível em: https://www.nelsonrosenvald.info/single-post/2017/12/05/O-novo-danomoral-trabalhista-\%E2\%80\%93-Um-ensaio-sobre-a-cegueira-do-legislador. Acesso em 05 set. 2018.

SANTOS, Enoque Ribeiro dos. O dano extrapatrimonial na Lei 13.467/17, da reforma trabalhista. Disponível em: http://genjuridico.com.br/2017/08/22/o-dano-extrapatrimonial-na-lei13-4672017-da-reforma-trabalhista/. Acesso em: 12 set. 2018.

SCHREIBER, Anderson. Novos paradigmas da responsabilidade civil: da erosão dos filtros da reparação à diluição dos danos. 2. ed. São Paulo: Atlas, 2009.

SIMÃO, José Fernando. Reforma Trabalhista. Dano extrapatrimonial: dano moral, estético e existencial? Parte III. Disponível em: http://www.cartaforense.com.br/conteudo/colunas/reforma-trabalhista-dano-extrapatrimonial-dano-moral-estetico-e-existencial-parte-iii/18004.

Acesso em 12 set. 2018.

SOARES, Flaviana Rampazzo. Responsabilidade civil por dano existencial. Porto Alegre: Livraria do Advogado, 2009.

TARTUCE, Flávio. Manual de direito civil: Volume Único. 8. Método, 12/2017.

Recebido em: 21 dez. 2018.

Aceito em: 28 jun. 2019. 